READERS' OPINION

\section{Citation indexing and the development of academic journals in tropical medicine}

\section{Derek R Smith}

Faculty of Health, University of Newcastle, Ourimbah, Australia, Anton Breinl Centre for Public Health, Tropical Medicine, James Cook University, Townsville, Australia

It has been suggested that the conquest of tropical diseases during the late XIX century represents one of modern medicines' greatest triumphs (Brennen \& Davey 1978). Much of the impetus for this achievement was spurred by the high prevalence of disease and epidemics that were at the time devastating new settlers, colonial servants or military occupiers within foreign colonial territories (Keiser \& Utzinger 2005). The formal study of tropical medicine can trace its origins to the Indian Medical Service of the British Army, which was founded in 1764 (Brennen \& Davey 1978). The Liverpool School of Tropical Medicine and the London School of Tropical Medicine began in April and October, respectively, of 1899 (Wilkinson \& Power 1998). With the arrival of pandemic plague to South America the Brazilian government founded the Instituto Soroterápico no Rio de Janeiro in 1900, which was later renamed after its famous director, Oswaldo Cruz (Momen \& Coura 2000). The Royal Society of Tropical Medicine and Hygiene was established at a "Meeting of Medical Men and Others Interested in Tropical Medicine" held in 1907 and where Sir Patrick Manson was elected president (Greenwood 2007). In 1929 the London School occupied a new premises and changed its name to the London School of Hygiene and Tropical Medicine, with a goal to centralize the study of all aspects of public health (Schilling \& McDonald 1990). It also offered a range of qualifications in various fields including both occupational and tropical medicine (Smith 1981).

For the most part, the early study of tropical medicine was dominated by parasitic and infectious diseases with an affinity for warm climates (Gilles \& Lucas 1998), and associated academic journals in the field reflected this trend. The formation of academic societies in tropical medicine was also followed by the publication of academic journals, the first English-language version being a short-lived publication known as the Annals of Military and Naval Surgery and Tropical Medicine and Hygiene in 1863 (Brennen \& Davey 1978). The publication of Manson's 1877 and 1878 articles on the microfilariae of elephantiasis and its metamorphosis in the mosquito

E-mail: derek.smith@newcastle.edu.au were seminal events in the field of tropical medicine, that would later provide the foundation for Ross's discovery of malaria transmission by Anopheles mosquitoes (Wilkinson \& Power 1998). In 1883 AF King had also published a somewhat obscure article in Popular Science Monthly where he proposed that mosquitoes might be a vector for malaria transmission (Chernin 1992). Transactions of the Royal Society of Tropical Medicine and Hygiene began concurrently with formation of the society in 1907 (Chernin 1992). In the same year the Memórias do Instituto Oswaldo Cruz was founded, with the first issue of volume one published in April 1909 (Coura 2006). The first North American journal focusing primarily on tropical diseases was the American Journal of Tropical Diseases and Preventive Medicine (New Orleans), founded in 1913 by Creighton Wellman of Tulane University (Chernin 1992). By the mid XX century, many former colonies had gained their independence and the discipline of tropical medicine expanded further still. Reflecting this trend, comparatively newer journals such as Acta Tropica and the American Journal of Tropical Medicine and Hygiene were founded in 1944 and 1952, respectively (Keiser \& Utzinger 2005).

As tropical medicine came of age, the dissemination of scientific information also expanded significantly, making it increasingly difficult for researchers and clinicians to keep up with current developments. To help scientists and librarians more clearly ascertain which journals were publishing the important literature in a given field, Eugene Garfield devised a method for determining and ranking the "impact" of scientific periodicals in 1955 (Garfield 1955). In what would later be termed the impact factor, Garfield's process utilized a relatively straightforward formula, whereby the articles published in a particular journal over a two-year period were traced to establish if they had been cited in another article's reference list in the following year. Garfield and his colleague Irving Sher had previously found that $25 \%$ of all citations to the current year's literature were only two to three years old, prompting them to choose two years as a cutoff period for citation counting which is still used today (Garfield 2007). The impact factor calculation worked then, as it does now, by dividing the number of citations in a given year to citable articles from the previous two-years, by the total number of citable articles published by the same journal over the same two-year period (Garfield 2006). Most journals now advertise a current impact factor on their websites, as published in the yearly Journal Citation Reports ${ }^{\circledR}$ by Thomson Scientific.

From being a tool used mainly by librarians in its early days, the impact factor has now risen to one of major debate within the academic world. Although certain intrinsic flaws have been described by various authors, perhaps the most important issue for public health journals is that most of the published scientific research is still being carried out in the developed world, even though numerous public health problems continue to exist in developing countries (Soteriades \& Falagas 2006). Similar to other sub disciplines such as occupational health (Smith 2007), tropical medicine also suffers from 
the two-year citation counting period that is used for calculating impact factors, meaning that diseases with long lag times will often go unrecognized and un-cited for many years (Coura \& Willcox 2003). Albert Sabin's groundbreaking research on the oral Polio vaccine (Sabin et al. 1960) is a classic example, having attracted fewer than 100 citations by the late 1980s (Garfield 1987). On the other hand, Oliver Lowry's laboratory methods article on the Folin Phenol reagent (Lowry et al. 1951) had received almost 300,000 citations by 2005 (Anonymous 2005). This clearly reveals a gap between what comprises a seminal discovery in tropical medicine research and what authors are actually inclined to cite.

The field of bibliometrics has been the subject of increasing interest in recent years and various authors have now investigated citation trends and impact factors in the discipline of tropical medicine. One of the earliest examples was published in 1978 as an analysis of citations indexed in the Tropical Diseases Bulletin between 1972 and 1975 (Brennen \& Davey 1978). In their pioneering investigation, the authors noted that a high concentration of tropical medicine articles were appearing in relatively few journals. English language was also observed as the most important publishing language in terms of productivity (Brennen \& Davey 1978). In 2001 Coura published a historical article to honor Professor Herman Lent (Coura 2001), finding that nearly one-third of his articles had been published in the journal Memórias do Instituto Oswaldo Cruz. In 2003, Coura and Willcox looked at impact factors, scientific production and the quality of Brazilian medical journals, including some titles which specifically focused on tropical medicine (Coura \& Willcox 2003). In 2004, Keiser and colleagues (Keiser et al. 2004) investigated the representation of authors and editors in tropical medicine journals.

A bibliographic analysis of articles in a single tropical medicine journal, Tropical Medicine and International Health, was published in 2004. In their examination of the time period 1996-2003, Glover and Bowen reported that malaria, HIV and schistosomiasis were the most commonly published topics (Glover \& Bowen 2004). An examination of citation patterns among 12 tropical medicine journals during 2002 revealed that the field bestowed approximately $40 \%$ more citations than it received, the core journals of tropical medicine cited each other heavily, and that there was significant reference to the general medicine and multidisciplinary science periodicals (Schoonbaert 2004). Perhaps the most comprehensive investigation of tropical medicine journals in recent years was an examination of 1,454 articles with 33,517 references in the 2004 literature (Hua 2005). Results from the study indicated that there were an average of 23 references per article and the self-citing rate was approximately $7 \%$. Brazil, the United States, India and England were identified as being some of the more advanced countries with regard to tropical medicine research (Hua 2005).

Keiser and Utzinger (2005) investigated 2,802 tropical medicine articles published between 1952 and 2002, finding a strong increase in the number of articles being published, as well as an overall doubling of the median number of authors per article (Keiser \& Utzinger
2005). Coura and Willcox (2005) looked at the development of impact factors at the Memórias do Instituto Oswaldo Cruz during 2005, finding an overall increase of the journal's score over time. An examination of tropical medicine research published between 1995 and 2003 (and published in 2006) revealed that developing areas of the world were now producing considerable amounts of research, although the mean impact factor of articles published in tropical medicine journals was still highest for the United States (Falagas et al. 2006). Interestingly, some of the earliest bibliometric analysis to include tropical medicine journals was conducted by the inventor of the impact factor himself, Eugene Garfield. In the 1908s, Garfield touched on the field of tropical medicine in some of his earlier citation analyses of schistosomiasis (Garfield 1986a), cholera (Garfield 1986b) and other research from the "third world" (Garfield 1983).

Over 50 years since they were first introduced, citation indexing and impact factors remain a mixed blessing when assessing the quality of tropical medicine research and their associated periodicals. Nevertheless, as we enter the XXI century the future of citation analysis in tropical medicine, as everywhere else in science, is difficult to predict. On one hand the overall size of most scientific fields has expanded rapidly. In citation indexing for example, the impact factor database has grown from 1.4 million citations in 1964 to 550 million in 2005, with the list of journals covered rising from 613 to 15,721 during the same period (Perkel 2005). On the other hand however, there remain many more pressing global issues for tropical medicine professionals to consider. Despite the existence of high quality journals for example, some scholars reported that qualitative information was still lacking and few results of studies performed in tropical countries had been published by the late XX century, particularly regarding tropical occupational health (Phoon 1982).

On a global scale it is also worth noting that tropical illnesses have by no means been eliminated, and it is the "neglected" tropical diseases that should now become the focus of our scientific efforts. According to Hotez et al. (2007), such diseases include helminth infections, lymphatic filariasis, onchocerciasis, dracunculiasis, schistosomiasis, Chagas disease, human African trypanosomiasis, leishmaniasis, Buruli ulcer, leprosy, and trachoma; with an expanded list including dengue fever, the treponematoses, leptospirosis, strongyloidiasis, foodborne trematodiases, neurocysticercosis and scabies (Hotez et al. 2007). It is the impact of tropical diseases themselves, research on these diseases, and the challenge of finding cost-effective and practical interventions to meet them, that should now dominate the future of scientific research and publishing in the field of tropical medicine.

\section{REFERENCES}

Anonymous 2005. Top 10 papers published. The Scientist 19: 26.

Brennen PW, Davey WP 1978. Citation analysis in the literature of tropical medicine. Bull Med Libr Assoc 66: 24-30.

Chernin E 1992. The early British and American journals of tropical medicine and hygiene: an informal survey. Med Hist 36: 70-83. 
Coura JR 2001. In honor to Herman Lent's 90 years and to his major contributions to the Memorias do Instituto Oswaldo Cruz. Mem Inst Oswaldo Cruz 96: 1029-1032.

Coura JR 2006. An up-to-date view of the evolution of Memorias do Instituto Oswaldo Cruz from 1907 to 2006. Mem Inst Oswaldo Cruz 101: 815-816.

Coura JR, Willcox LC 2003. Impact factor, scientific production and quality of Brazilian medical journals. Mem Inst Oswaldo Cruz 98: 293-297.

Coura JR, Willcox LC 2005. Impact factor evolution on Memorias do Instituto Oswaldo Cruz. Mem Inst Oswaldo Cruz 100: 457-458.

Falagas ME, Karavasiou AI, Bliziotis IA 2006. A bibliometric analysis of global trends of research productivity in tropical medicine. Acta Trop 99: 155-159.

Garfield E 1955. Citation indexes for science: a new dimension in documentation through association of ideas. Science 122: 108-111.

Garfield E 1983. Mapping science in the Third World. Part 2. Essays Inf Sci 6: 265-275.

Garfield E 1986a. Schistosomiasis: The scourge of the Third World, Part 2. diagnosis and treatment. Essays Inf Sci 9: 70-80.

Garfield E 1986b. Mapping Cholera research and the impact of Shambu Nath De of Calcutta. Essays Inf Sci 9: 103-111.

Garfield E 1987. 100 citation classics from the Journal of the American Medical Association. JAMA 257: 52-59.

Garfield E 2006. The history and meaning of the journal impact factor. JAMA 295: 90-93.

Garfield E 2007. The evolution of the Science Citation Index. Int Microbiol 10: 65-69.

Gilles HM, Lucas AO 1998. Tropical medicine: 100 years of progress. Br Med Bull 54: 269-280.

Glover SW, Bowen SL 2004. Bibliometric analysis of research published in Tropical Medicine and International Health 1996-2003. Trop Med Int Health 9: 1327-1330.

Greenwood B 2007. Royal Society of Tropical Medicine and Hygiene: 100 years old. Lancet 370: 811-813.

Hotez PJ, Molyneux DH, Fenwick A, Kumaresan J, Sachs SE, Sachs
JD, Savioli L 2007. Control of neglected tropical diseases. $N$ Engl J Med 357: 1018-1027.

Hua Y 2005. The feature of papers and citation analysis of eleven journals in tropical medicine indexed by Science Citation Index Expanded. Mem Inst Oswaldo Cruz 100: 805-810.

Keiser J, Utzinger J 2005. Trends in the core litertaure on tropical medicine: A bibliometric analysis from 1952-2002. Scientometrics 62: 351-365.

Keiser J, Utzinger J, Tanner M, Singer BH 2004. Representation of authors and editors from countries with different human development indexes in the leading literature on tropical medicine: survey of current evidence. BMJ 328: 1229-1232.

Lowry OH, Rosebrough NJ, Farr AL, Randall RJ 1951. Protein measurement with the Folin phenol reagent. J Biol Chem 193: 265-275.

Momen H, Coura JR 2000. Instituto Oswaldo Cruz: first centenary (1900-2000). Parasitol Today 16: 361-362.

Perkel JM 2005. The future of citation analysis. The Scientist 19: 24-25.

Phoon WO 1982. Recent developments in occupational health in tropical countries. Trop Dis Bull 79: 653-666.

Sabin AB, Ramos-Alvarez M, Alvarez-Amezquita J, Pelon W, Michaels RH, Spigland I, Koch MA, Barnes JM, Rhim JS 1960. Live, orally given poliovirus vaccine. Effects of rapid mass immunization on population under conditions of massive enteric infection with other viruses. JAMA 173: 1521-1526.

Schilling RS, McDonald JC 1990. Occupational health at the London School of Hygiene \& Tropical Medicine. Br J Ind Med 47: 135-137.

Schoonbaert D 2004. Citation patterns in tropical medicine journals. Trop Med Int Health 9: 1142-1150.

Smith CE 1981. The London School of Hygiene and Tropical Medicine. Trans R Soc Trop Med Hyg 75 (Suppl): 12-20.

Smith DR 2007. Historical development of the journal impact factor and its relevance for occupational health. Ind Health 45: 730-742.

Soteriades ES, Falagas ME 2006. A bibliometric analysis in the fields of preventive medicine, occupational and environmental medicine, epidemiology, and public health. BMC Public Health 6: 301.

Wilkinson L, Power H 1998. The London and Liverpool Schools of Tropical Medicine 1898-1998. Br Med Bull 54: 281-292. 